\author{
Antonieta Middea ${ }^{1,2}$, Marisa Bezerra de Mello Monte ${ }^{2}$ \\ and Elizabete Fernandes Lucas ${ }^{1}$
}

\title{
THE INFLUENCE OF THE SOLVENT MEDIUM ON THE AGGREGATION OF ASPHALTENE MACROMOLECULES AND DETERMINATION OF THEIR MOLAR MASS
}

\author{
${ }^{1}$ Institute of Macromolecules, Federal University of Rio de Janeiro, Brazil \\ ${ }^{2}$ Mineral Technological Center (CETEM), Ih a do Fundro, RJ, Brazil \\ amiddea@cetem.gov.br; elucas@ima.ufrj.br
}

Received: March 18, 2008

\begin{abstract}
The formation of aggregates of a fraction of asphaltenes extracted from Brazilian crude oil was investigated by measuring the interfacial tension and kinematic viscosity of their solutions prepared in different solvents. The interfacial tension results indicate the existence of critical micelle concentration (CMC) levels of the asphaltenes in solvents with solubility parameters sufficiently different from those of the asphaltene tested. The kinematic viscosity measures revealed the formation of aggregates at concentrations above the CMC. The interfacial tension measures of asphaltenes in organic solutions, although infrequently mentioned in the literature, were used to calculate the molar mass, permitting the comparison of various molar masses attributed to the asphaltenes in the form of aggregates.
\end{abstract}

Key words: crude oil, asphaltenes, aggregation, viscosity, interfacial tension, molar mass.

\section{Introduction}

Asphaltenes are compounds with high molar mass that compose the heavier and more polar fractions of petroleum. These fractions precipitate with the addition of alkanes with low molar mass, such as $n$-pentane, $n$ hexane or $n$-heptane, and are soluble in solvents such as toluene and benzene. Regarding their chemical composition, it is known that they are formed by molecules of paraphinic, naphthenic or aromatic hydrocarbons and also have functional groups that contain oxygen, nitrogen or sulfur. The fractions that are soluble in $n$-heptane correspond to the resins, aromatics and saturates. These fractions are selectively separable by adsorption in silica gel or alumina [1,2].

Asphaltenes have the capacity to aggregate and be adsorbed at the interfaces. When aggregating they can form undesirable solid deposits that reduce oil recovery. When they adsorb at the oil-water interface, these components stabilize water-in-oil emulsions by forming a mechanical barrier to the agglutination of the droplets during collisions. This phenomenon is responsible for the production of oil in the form of a water-in-oil emulsion, prompting the need for a demulsification step, which corresponds to the separation of the oil and the water, since the presence of water in oil, among other negative effects, hinders its transport and refining. At the gas-oil interface, asphaltenes can contribute to the formation of very stable natural gas foams in crude oil $[3,4]$.

The physical and thermodynamic properties of asphaltenes have been extensively studied, along with their behavior in petroleumduring its extraction [5]. Nevertheless, there is still much to learn about their chemical structure and behavior, because (1) asphaltenes are not made up of a single molecule, but rather a family of molecules with similar structures in terms of molar mass and polarity, since they are isolated from petroleum by processes involving solubility, and (2) the proportion and chemical structure of asphaltenic fractions vary depending on the crude oil origin. Hence, they can behave in distinct ways.

The study of the physical and thermodynamic properties and the chemical composition of the constituents of petroleum is very important for all operations in this industry. The presence of the heavy fraction in crude oil, even in relatively small proportions, has important influences on the behavior of the petroleum fluid phases in the conditions found during its extraction, transport and refining. The chemical makeup, relative proportion and interaction of this fraction with the fluid other constituents significantly influence some of the important properties and phenomena, such as the flash point of natural gas, precipitation of paraffins in oils submitted to low temperatures (deepwater pipelines) and destabilization and deposition of asphaltenes in the reservoir and production column, due to changes in the composition and temperature and pressure conditions during oil production and transport operations. 
Determination of molar mass, one of the most important properties of asphaltenes, is difficult because of their tendency to agglomerate and to associate with other oil constituents. The various methods of determining molar mass can supply different results because of these aggregations.

Various measurement techniques are employed, such as vapor pressure osmometry (VPO) and size exclusion chromatography (SEC), suggesting high molar masses between 1000 and 10000 [6]. The technique of measuring the interfacial tensions of asphaltenes in organic solutions, although infrequently cited in the literature, can be used to calculate the molar mass, allowing comparison of the masses attributed to the asphaltenes obtained by other methods in the form of aggregates [7-9].

This determination can be done by obtaining the interfacial tension versus asphaltene concentration curve of the asphaltene in a given solvent, measured at the airsolution interface. The surface concentration of the species adsorbed $(\Gamma)$ can be calculated by taking the slope of the curve before reaching the $\mathrm{CMC}$ and applying the Gibbs isotherm equation (Equation 1) [10]:

$$
\Gamma=-1 / R T \cdot d \gamma / d \ln C
$$

where: $\Gamma$ is the surface concentration of the species adsorbed $\left(\mathrm{mol} / \mathrm{m}^{2}\right) ; R$ and $T$ are the constants, $8.31451 \mathrm{~J} / \mathrm{K} \cdot \mathrm{mol}$ and $298.15 \mathrm{~K}$ respectively; and $d \gamma / d \ln C$ is the variation of interfacial tension as a function of the natural log of the sample concentration obtained through the angular coefficient of the curve $\left(\mathrm{mJ} / \mathrm{m}^{2}\right)$.

It is also possible to estimate the molecular area of the material adsorbed at the interface $\left(A_{a}\right)$ through Equation 2 [11]:

$$
A_{a}=1 / N_{a} \Gamma
$$

where: $A$ is the area occupied by one asphaltene molecule $\left(\AA^{2}\right)$ and $N_{a}$ is Avogadro's number $\left(6.02 \cdot 10^{23} \mathrm{~mol}^{-1}\right)$.

Assuming a circular geometry for the asphaltenes adsorbed at the interface [12], one can estimate the asphaltene radius $(R, \AA)$ as:

$$
R=\left[A_{a} / 4 \pi \cdot 1.4 \cdot(1.72)^{1 / 3}\right]^{1 / 2}
$$

In this way, the molar mass $(M M, \mathrm{~g} / \mathrm{mol})$ of the asphaltenes can be calculated by Equation 4 [12]:

$$
M M=h \cdot \pi \cdot R^{2} \cdot D \cdot N_{a}
$$

where: $h$ is the estimated height of the cylindrical

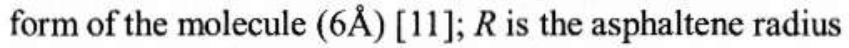
(E); and $D$ is the density $\left(1.1 \mathrm{~g} / \mathrm{cm}^{3}\right)[11]$.

The molar masses obtained in this way have lower values than those obtained by other methods [13]. The molar masses of asphaltenes also vary significantly depending on the particular asphaltenes chemical structure in the solution, the polarity of the solvent used and the temperature at which the tests are performed.

In this work we determined the asphaltenes molar mass by the interfacial tension technique, which is simple and inexpensive and supplies more realistic values since what is probably being measured is the molar mass of the asphaltene unimer. In addition to that, we evaluated the mechanisms by which asphaltene aggregates form - a subject of great importance in the petroleum industry because it helps to resolve asphaltene deposition related problems.

\section{Experimental}

\subsection{Materials}

We used the following materials: $n$-heptane P.A. and toluene P.A., from Vetec Quimica Fina Ltda., Brazil; methylnaphthalene P.A., nitrobenzene P.A., pyridine P.A. and tetrahydrofuran P.A., from Merck KGaA, Germany; and a sample of crude oil from a Brazilian field. The main characteristics of the solvents and the oil sample are shown in Tables 1 and 2 respectively.

\subsection{Extraction of the asphaltenes}

We obtained the asphaltene by extraction from the petroleum through adaptation of the method of Calema et al. [15], which basically consists in precipitation of the asphaltenes by $\mathrm{n}$-heptane in a Soxhlet extractor for eight hours. Our modifications in this study were to use $60 \mathrm{ml}$ of heptane to $5 \mathrm{~g}$ of crude oil and to continue the extraction exhaustively in the Soxhlet device for $120 \mathrm{~h}$. Visible ultraviolet light was used to detect maltene impurities in the asphaltene extracted, during the time intervals, related to the reduction in the brown color range present in the heptane during extraction. The precipitated asphaltenes were washed with excess heptane, vacuum dried and then solubilized with toluene and filtered to remove possible carboids present in the sample. The asphaltene obtained was then stored in a dark place at low temperature to prevent any modification of its original structure.

\subsection{Ultraviolet spectrometry analysis}

For the ultraviolet spectrometry tests we used a LaMotte AC 1500 Smart Spectro ultraviolet spectrophotometer with a quartz cuvette with a $1-\mathrm{mm}$ path, at a wavelength of 350 to $950 \mathrm{~nm}$. The method employed in this experiment basically consisted in measuring the absorbances of the oil in heptane solutions at different extraction times.

\subsection{Characterization of the asphaltene by Fourier transform infrared spectrometry (FTIR)}

To characterize the asphaltene we used a Bomen MB 102 infrared spectrophotometer and DTGS (deuterated triglycine sulfate) as a detector, with cesium iodide (CsI) windows. We used the diffuse reflectance 
Main solvent characteristics

\begin{tabular}{|c|c|c|c|c|}
\hline Solvent & $\begin{array}{c}\text { Molar mass } \\
(\mathrm{g} / \mathrm{mol})\end{array}$ & Structure & $\begin{array}{c}\text { Volatilization } \\
\text { temperature } \\
(\mathrm{K})\end{array}$ & $\begin{array}{c}\text { Solubility parameter } \\
\left(\mathrm{MPa}^{1 / 2}\right)[14]\end{array}$ \\
\hline Nitrobenzene & 123 & 483.8 & 22.2 \\
\hline Pyridine & 79 & & 388.3 & 21.8 \\
\hline Tetrahydrofuran & 72 & & 339.0 & 19.4 \\
\hline Toluene & 92 & & 383.6 & 18.2 \\
\hline Methylnaphthalene & 142 & & 518.0 & \\
\hline
\end{tabular}

Table 2

Main characteristics of the oil used*

\begin{tabular}{|c|c|}
\hline Characteristics & Content (\%) \\
\hline Saturates / Aromatics & 1.6 \\
\hline N, S, and O & 26.8 \\
\hline Resins & 25.1 \\
\hline Asphaltenes (IP143) & 3.1 \\
\hline Paraffins & 8.1 \\
\hline $\begin{array}{c}\text { Molar mass of the asphaltenes (by vapor pressure osmometry } \\
\text { using toluene as a solvent, at 298 K) }\end{array}$ & $\sim 5000$ \\
\hline API Degree (ASTM D4052) & 20.2 \\
\hline
\end{tabular}

* Data supplied by CENPES/Petrobras.

(DR) method, aiming to maximize the sensitivity of the surface analysis of the asphaltene powders.

To obtain the spectrum, we mixed $20 \mathrm{mg}$ of the asphaltene sample with $220 \mathrm{mg}$ of $\mathrm{KBr}$ and then transferred the mixture to the receptacle of the diffuse reflectance accessory. The spectrophotometer chamber was purged with nitrogen for $2 \mathrm{~h}$ at a flow of 5 psi to remove the $\mathrm{CO}_{2}$ and $\mathrm{H}_{2} \mathrm{O}$ before obtaining the spectrum. We carried out 1000 scans at a velocity of 20 scans $/ \mathrm{min}$ and a resolution of $4 \mathrm{~cm}^{-1}$, analyzing the spectrum at a frequency interval between 4000 and $400 \mathrm{~cm}^{-1}$.

\subsection{Interfacial tension measures}

We obtained the interfacial tension measures using the Du Nouy method in a Sigma 70 automatic tensiometer from KSV Instruments Ltd., at a temperature of $298 \mathrm{~K}$, as a function of the asphaltene concentration in solutions of toluene, pyridine, nitrobenzene, tetrahydrofuran or methylnaphthalene, to determine the critical micelle concentration (CMC). We obtained the successive asphaltene solutions starting from a concentration of $1 \%$ asphaltene by weight and then determined the molar masses from the interfacial tension versus asphaltene concentration curves [2]. 


\subsection{Kinematic viscosity measures}

We measured the kinematic viscosity using glass capillary viscosimeters, performing the measurements in triplicate, at asphaltene concentrations varying from 0.0001 to $1.0 \% \mathrm{p} / \mathrm{v}$ and at a temperature of $298 \mathrm{~K}$ with increments of $283 \mathrm{~K}$.

\section{Results and Discussion}

\subsection{Extraction of the asphaltenes}

The maltene fraction soluble in n-heptane was extracted from the petroleum in the Soxhlet extractor, with the precipitate remaining behind, consisting of asphaltene macromolecules, carbenes and carboids. The extraction process was monitored by ultraviolet analysis of the solutions of $n$-heptane containing maltenes. At the end of the extraction, the heptane solvent located in the upper part of the extractor should be clean, meaning that the entire maltene fraction was extracted from the petroleum. Figure 1 shows the absorbance versus wavelength curves at a range of 350 to $950 \mathrm{~nm}$, obtained for the n-heptane solutions collected after extraction times of 8,72 and $120 \mathrm{~h}$. The maximum absorbance values varied with extraction time and composition of the maltene fractions. The maximum absorbances occurred at 450 and $500 \mathrm{~nm}$. We plotted the absorbance $v s$ time for these two wavelengths (Fig. 2). It can be seen that the absorbance value fell with time, indicating the decreasing variation of the maltene concentration in the asphaltene precipitate obtained.

We performed three extractions, with an average yield of $5.1 \%$, to obtain the necessary quantity of asphaltenes for this work. This yield is higher than that obtained by the IP 143 method ( $3.1 \%$, as shown in Table 2), suggesting that the method utilized in this study enables higher yields than the traditional IP 143 extraction method. In that method, however, the extraction time is only 60 minutes without the need to monitor the maltene residues.

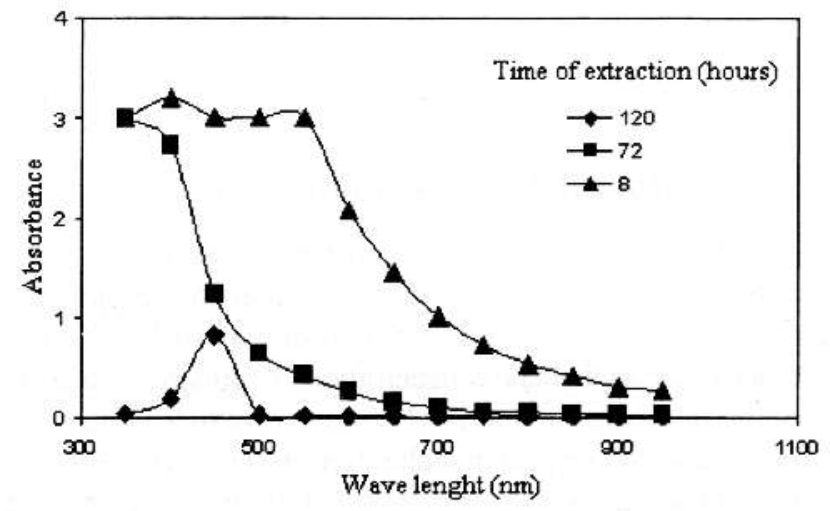

Fig. 1. Absorption spectrograph in the $350-950 \mathrm{~nm}$ range of the solutions collected from the Soxhlet extractor at three different times

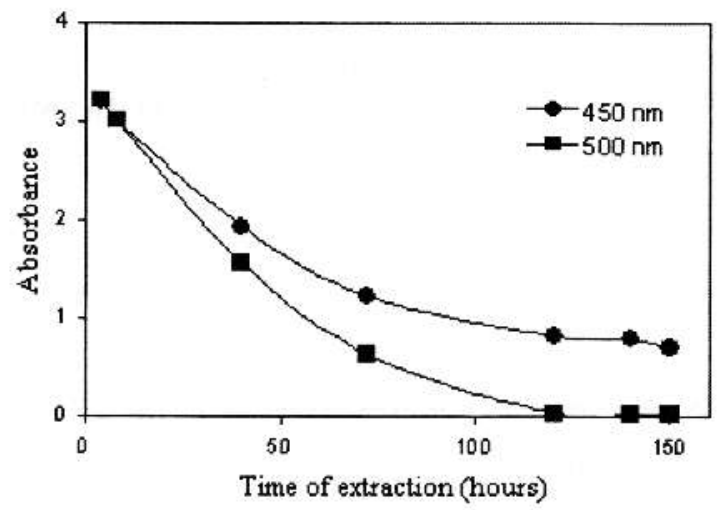

Fig. 2. Influence of contact time between the $n$-haptane solution and petroleum in the visible absorption spectrum in the wash solutions containing maltenes

\subsection{Characterization of the asphaltenes by FTIR}

The characterization of the asphaltenes obtained by Fourier transform infrared spectrometry shows peaks in the region between 2850 and $2920 \mathrm{~cm}^{-1}$, which correspond to the symmetric and asymmetric axial deformations of the $\mathrm{C}-\mathrm{H}$ groups, indicating that this asphaltene has significant quantities of aliphatic $\mathrm{C}-\mathrm{H}$. This can also be confirmed by the peaks in the 1455 and $1375 \mathrm{~cm}^{-1}$ regions, originating, respectively, from the symmetric angular deformation in the methylene plane and the $\mathrm{C}-\mathrm{H}$ bonds of the methyl group.

On the other hand, the band observed at $1605 \mathrm{~cm}^{-1}$ and the peaks located at 800,870 and $790 \mathrm{~cm}^{-1}$ correspond to angular deformations outside the plane of the $\mathrm{C}=\mathrm{C}$, $\mathrm{C}=\mathrm{O}$ and $\mathrm{C}-\mathrm{H}$ aromatic ring bonds, respectively. At around $3300 \mathrm{~cm}^{-1}$ a broad band can be observed resulting from the axial deformation of the $\mathrm{O}-\mathrm{H}$ group, and at $1032 \mathrm{~cm}^{-1}$ there is a characteristic peak of $\mathrm{C}_{2} \mathrm{~S}=\mathrm{O}$.

This result coincides with those observed by other authors $[16,17]$ and has similarities with the structure of the asphaltenes presented in Fig. 2, basically forming a polyaromatic structure with some heteroatoms $(\mathrm{N}, \mathrm{S}$ and $\mathrm{O})$ and pending alkyl groups for the most part consisting of carbon and hydrogen atoms.

\subsection{Determination of molar mass of the asphaltenes}

The molar masses of the asphaltenes extracted from the oil were calculated from the interfacial tension curves obtained experimentally for the asphaltene solubilized in toluene, pyridine, nitrobenzene, tetrahydrofuran or methylnaphthalene at $298 \mathrm{~K}$. The adsorption density of the species at the air-solution interface $(\Gamma)$ was obtained by using the slope of the curve before reaching the $\mathrm{CMC}$ and applying the Gibbs isotherm equation (Eq. 1). First we determined the interfacial tension values of the pure solvent which coincided with those described in the literature [18]. 
The interfacial tension curves for the asphaltene concentration at $298 \mathrm{~K}$, in the pyridine, nitrobenzene and tetrahydrofuran solvents show declining tension values with increasing asphaltene concentration and indicate the existence of a critical micelle concentration (CMC) due to the discontinuity of the curves. We did not observe this phenomenon when the asphaltene was dissolved in toluene or methylna- phthalene, possibly due to the high solubility of asphaltene in these two solvents. We also did not observe any variation in the interfacial tension, so it was not possible to calculate the molar mass of the asphaltene dissolved in these two solvents.

Table 3 shows the parameters utilized to calculate the molar mass of the asphaltene in pyridine, nitrobenzene and tetrahydrofuran.

Table 3

Parameters used to calculate the molar mass of asphaltene in different solvents at $298 \mathrm{~K}$

\begin{tabular}{|c|c|c|c|c|c|c|}
\hline Solvent & $\begin{array}{c}\mathrm{CMC} \\
(\%)\end{array}$ & $\begin{array}{c}d \gamma / d \ln C \\
\left(\mathrm{~mJ} / \mathrm{m}^{2}\right) .\end{array}$ & $\begin{array}{c}\Gamma \\
\left(\mathrm{mol} / \mathrm{m}^{2}\right)\end{array}$ & $\begin{array}{c}A_{a} \\
\left(\AA^{2}\right)\end{array}$ & $\begin{array}{c}R \\
\left(\AA^{2}\right)\end{array}$ & $\begin{array}{c}M M \\
(\mathrm{~g} / \mathrm{mol})\end{array}$ \\
\hline Nitrobenzene & 0.09 & -0.7905 & $3.189 \cdot 10^{-7}$ & 520.89 & 4.97 & 308.16 \\
\hline Pyridine & 0.20 & -0.3182 & $1.284 \cdot 10^{-7}$ & 1293.71 & 7.84 & 766.83 \\
\hline Tetrahydrofuran & 0.35 & -0.1188 & $4.792 \cdot 10^{-8}$ & 3466.24 & 12.83 & 2053.63 \\
\hline Methylnaphthalene & - & - & - & - & - & - \\
\hline Toluene & - & - & - & - & - & - \\
\hline
\end{tabular}

The areas occupied by one asphaltene molecule, in the range of 520 to $3500 \AA^{2}$, coincide with the values obtained in the previous studies [8]. The molar mass values calculated for this asphaltene present a band well below the range of values obtained by other methods, suggesting that these other methods measure the molar mass of molecular aggregates [13]. The asphaltenes molar masses show pronounced variations that depend on the asphaltene concentration in the solution, the solvent polarity and temperature used. The high polarity of nitrobenzene means that the molar mass observed is compatible with the expected values in structural determinations such as $\mathrm{RMN}-\mathrm{H}^{1}$ [13]. More aggregates were formed in tetrahydrofuran than in nitrobenzene or pyridine (solvents having less affinity with asphaltene compared to tetrahydrofuran in solubility parameter terms). This is probably due to the fact that at high solubility parameter values (nitrobenzene and pyridine, with 22.4 and $21.8 \mathrm{MPa}$ respectively), the polar groups are more solvated, while the apolar groups need to agglomerate to expose less area to the solvent. This occurs even at small concentrations. Since they are extensive groups surrounded by solvated polar groups, this type of aggregation does not involve many molecules. In contrast, at low solubility parameters, the apolar groups are more solvated and the association occurs only at higher concentrations.

\subsection{Effect of the asphaltene concentration on the kinematic viscosity and aggregation in solvents}

The kinematic viscosities as a function of the asphaltene concentration in nitrobenzene, pyridine, tetrahydrofuran, toluene and methylnaphthalene, at $298 \mathrm{~K}$, are shown in Figures 3, 4, 5, 6 and 7 respectively. Figures 3 to 5 show two distinct behavior patterns. In the first one, the viscosity increases as the asphaltene concentration rises until a determined concentration, after which the viscosity climbs more steeply as the asphaltene concentration increases. The discontinuity points occur near the respective $\mathrm{CMC}$ values of each system. Below the $\mathrm{CMC}$, the viscosity increases only because of the increased concentration of solids. Above the CMC, it increases both because of the higher concentration of solids and the increased size of the aggregate, resulting in a more accentuated increase in viscosity.

For the systems in toluene and methylnaphthalene (Figures 6 and 7), only the first behavior occurred - a gradual increase in viscosity with rising concentration. Within the concentration range tested, we did not observe any discontinuity characteristic of the CMC. These results corroborate those obtained for the interfacial tension of these same systems.

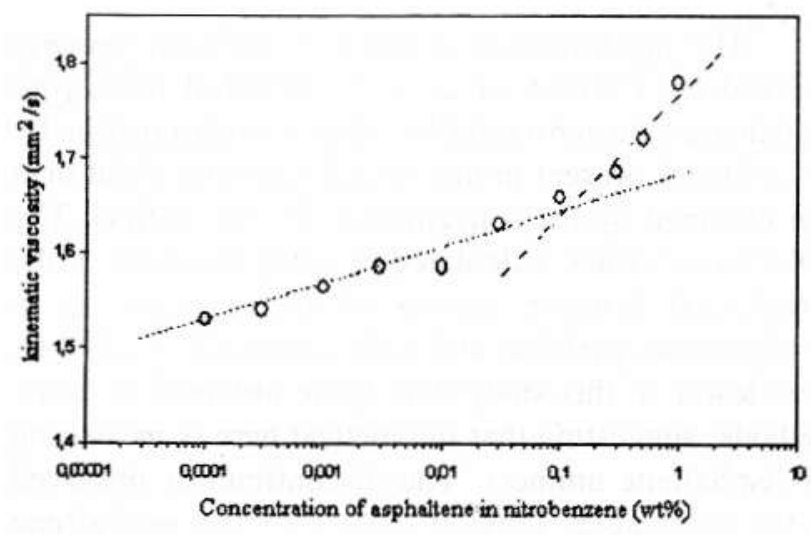

Fig. 3. Kinematic viscosity as a function of asphaltene concentration in nitrobenzene, at $298 \mathrm{~K}$

$(\mathrm{CMC}=0.09 \% \mathrm{p} / \mathrm{v})$, measurement error: \pm 0.2 


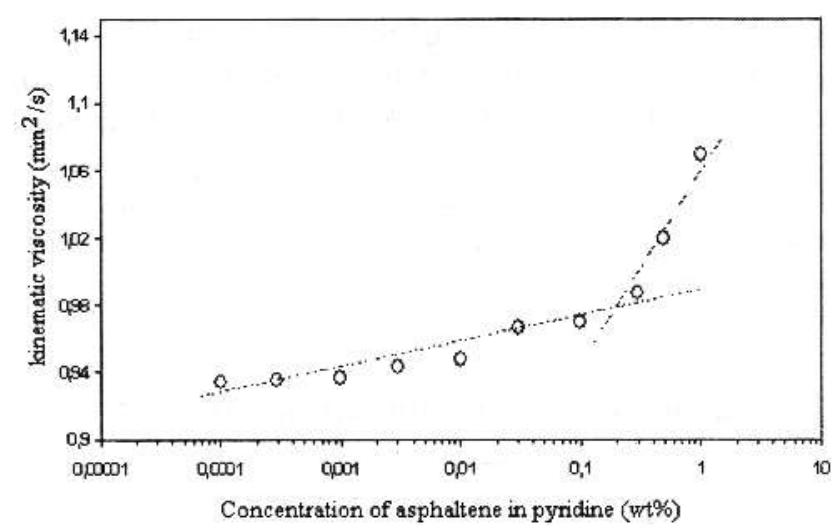

Fig. 4. Kinematic viscosity as a function of asphaltene concentration in pyridine, at $298 \mathrm{~K}(\mathrm{CMC}=0.20 \% \mathrm{p} / \mathrm{v})$, measurement error: \pm 0.5

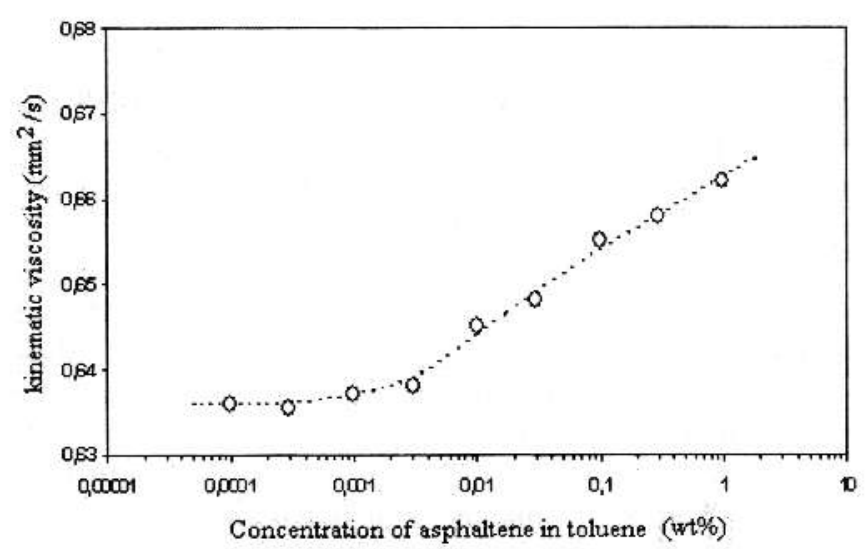

Fig. 6. Kinematic viscosity as a function of asphaltene concentration in toluene, at $298 \mathrm{~K}(\mathrm{CMC}>1.0 \% \mathrm{p} / \mathrm{v})$, measurement error: \pm 0.4

\section{Conclusions}

The optimization of the conventional process utilized by Calema et al. [15] enabled obtaining asphaltene with substantially reduced contamination by the maltenes present in the oil and a greater yield than that obtained by the conventional IP 143 method. The molar mass values, calculated by using the slope of the interfacial tension curves of the asphaltene in nitrobenzene, pyridine and tetrahydrofuran, at $298 \mathrm{~K}$, were lower in this study than those obtained by other methods, suggesting that the method here is measuring the asphaltene unimers. The discontinuities observed in the interfacial tension curves of the asphaltene solutions in nitrobenzene and pyridine, varying with the asphaltene concentration, are indications of an aggregation process.

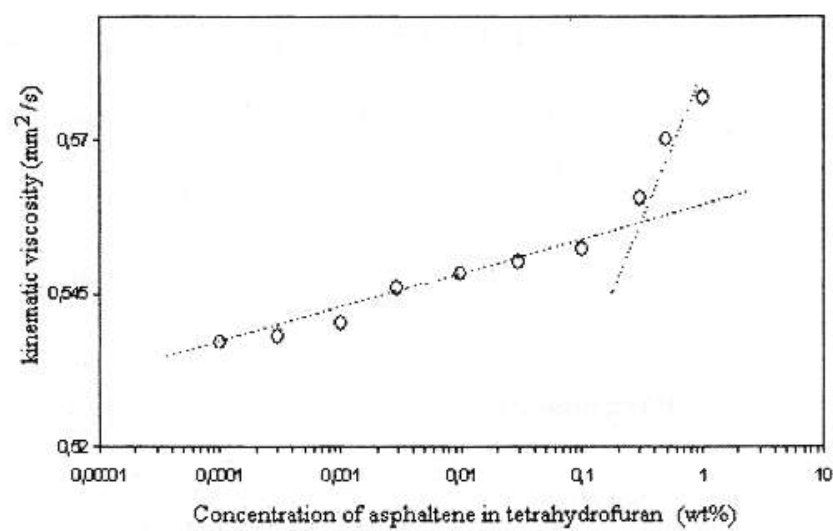

Fig.5. Kinematic viscosity as a function of asphaltene concentration in tetrahydrofuran, at $298 \mathrm{~K}$ $(\mathrm{CMC}=0.35 \% \mathrm{p} / \mathrm{v})$, measurement error: \pm 0.3

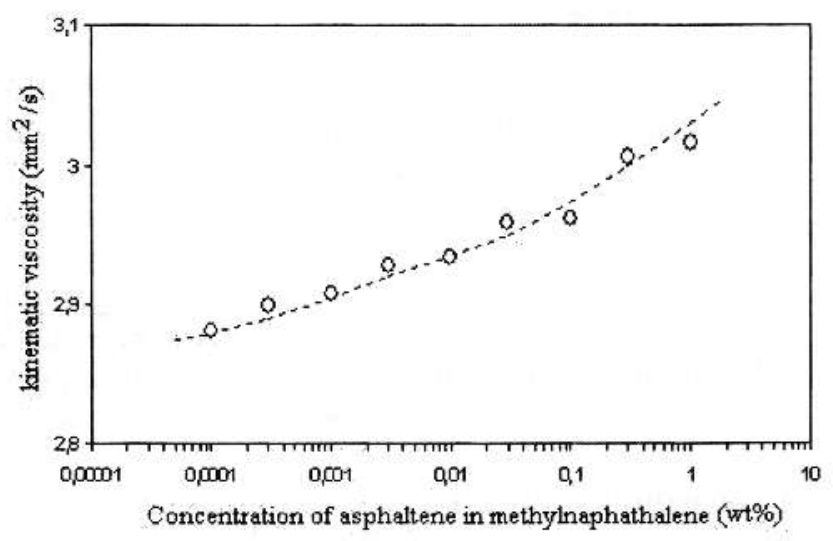

Fig. 7. Kinematic viscosity as a function of asphaltene concentration in methylnaphthalene, at $298 \mathrm{~K}$ $(\mathrm{CMC}>1.0 \% \mathrm{p} / \mathrm{v})$, measurement error: \pm 0.3

\section{Acknowledgements}

CETEM, Petrobras, CNPq and CAPES

\section{References}

[1] Hong E. and Watkinson P.: Fuel, 2004; 83, 1881.

[2] Trejo F., Centeno G. and Ancheyta J.: Fuel, 2004, 83, 2169.

[3] McLean J. and Kilpatrick P.: J. Colloid Interface Sci., 1997, $189,242$.

[4] Andersen S., Rio J., Khvostitchenko D., Shakir S. and Galeana C.: Langmuir, 2001, 17, 307.

[5] Spiecker P., Gawrys K. and Kilpatrick P.: J. Colloid Interface Sci., 2003, 267, 178.

[6] Speight J., Wernick D., Gould K., Overfield R., Rao B. and Savage D.: Revue de L'Institut Francais du Petrole, 1985, 40, 51.

[7] Moschopedis S., Fryer I. and Speight I.: Fuel, 1976, 55, 227. 
[8] Monte M., Coelho R. and Middea A.: Petrol. Sci. \& Techn., 2004, 22 (7\&8), 991.

[9] Strausz O., Peng P. and Murgich J.: Energy \& Fuels, 2002, 16,809 .

[10] Sheu E.: J. Phys. \& Condensed Matter, 1996, 8, A121.

[11] Priyanto S., Mansoori G. and Suwono A.: Chem. Eng. Sci., 2001, 56, 6933.

[12] Yudin I., Nikolaenko G., Gorodetskii E., Markhashov E., Agayan V., Anisimov M. and Sengers J.: Physica A, 1998, 251, 235.

[13] Yarranton H., Alboudwarej H. and Jakher R.: Ind. \& Eng. Chem. Res., 2000, 39, 2916.

[14] Barton A.: Handbook of Solubility Parameters, 1983.

[15] Calema V., Iwanski P., Nali M., Scotti R. and Montanari L.: Energy \& Fuels, 1995, 9, 225.

[16] Dehkissia S., Larachi F., Rodrigue D. and Chornet E.: Fuel, 2004, 83, 2157.

[17] Sousa M., Oliveira G., Lucas E. and Gonzalez G.: Progress in Colloid and Polymer Science, 2004, 128, 283.

[18] Lide D.R.: Handbook of Chemistry and Physics. $75^{\text {th }}$ ed.

\section{ВПЛИВ СЕРЕДОВИЩА РОЗЧИННИКА НА АГРЕГАЦІЮ АСФАЛЬТЕНОВИХ МАКРОМОЛЕКУЛ I ВИЗНАЧЕННЯ ЇХ МОЛЕКУЛЯРНОЇ МАСИ}

Анотація. Вивчено утворення агрегатів фракції асфальтенів із сирої бразильської нафти, приготовленої в різних розчинниках внаслідок вимірювання міжсфазного натягу і кінематичної в 'язкості розчинів. Міжфазний натяг вказус иа присутність критичної концентрачіі мічели (ККМ) асфальтенів в розчинниках з параметрами розчинності, які суттєво відрізняються від параметрів випробувапих асфальтенів. Кінематична в 'язкість вказує на утворення агрегатів при конуентраціях вицих за ККМ. Величини міжсфазного иатягу асфальтенів у органічних розчинииках, хоча $і$ не часто зустрічаються y літературі, використовувались для розрахунку молекуляриих мас, цо дозволило порівняти різні молекулярні маси асфальтенів у формі агрегатів.

Ключові слова: сира нафта, асфальтени, агрегауія, в 'ззість, міжфазний натяг, молекулярна маса 